\title{
Medicinas e plantas medicinais nos trópicos: aspectos da constituição da ciência farmacêutica ocidental
}

\author{
Medicines and medical plants in the tropics: on the \\ development of Western science of pharmacy
}

\author{
Carlos Eduardo Calaça \\ Mestre em história social pela Universidade de São Paulo (USP), \\ onde faz seu doutoramento com bolsa da Fundação de Amparo à \\ Pesquisa do Estado de São Paulo (Fapesp) \\ calaca@urbi.com.br
}

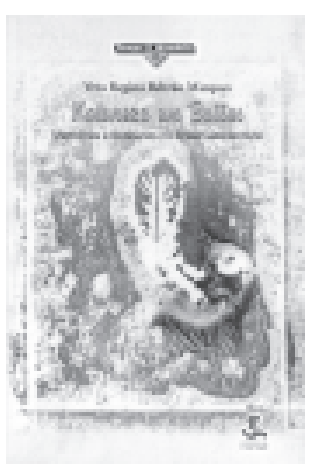

Natureza em Boiões: medicinase boticários no Brasil setecentista.

Vera Regina Beltrão Marques

Campinas, Editora da Unicamp/Centro de Memória, Unicamp, 1999
$\mathrm{O}$ universo dos saberes e das práticas medicinais no período colonial vem sendo tema de importantes trabalhos. Somando-se à recente pesquisa de Márcia Moisés Ribeiro - que resultou no livro A ciência dos trópicos: a arte médica no Brasil do século XVIII -, Natureza em Boiões: medicinas e boticários no Brasil setecentista, de Vera Regina Beltrão Marques, oferece-nos uma contribuição original ao estudo do problema.

Natureza em Boiões apresenta uma questão fundamental: a diversidade das raízes culturais das populações aqui residentes, mais do que a falta de médicos, teria sido crucial para a persistência de práticas de curas plurais nos trópicos. Em última instância, parte dos medicamentos receitados pelos doutos coimbrãos seria constituída por fórmulas resultantes da aproximação das culturas presentes no Brasil. Mesmo vulgarizados, muitos desses saberes provinham da intuição e do uso secular daqueles curandeiros e pajés conhecedores das matas, em caminhos nunca dantes palmilhados pelos colonizadores. Saberes muitas vezes relegados no plano do discurso por parte dos colonizadores, na prática, teriam sido fundamentais para a constituição da ciência farmacêutica moderna do Ocidente.

Contudo, se a princípio, supõe-se que os protagonistas da trama sejam integrantes do grupo de colonizadores - no caso, os boticários, que inclusive fazem parte do subtítulo do livro, - , ou mesmo dos colonizados, percebe-se, no decorrer da obra, que tanto os primeiros quanto os segundos são 'atores coadjuvantes', pois o foco de atenção da autora está nas plantas consideradas medicinais, originárias da natureza brasílica e que, aos poucos, vão sendo intuídas, utilizadas, 'lidas', dadas a ver, decifradas, classificadas (de acordo com critérios diferenciados no tempo), encaixotadas, exportadas para a metrópole para, por fim, serem para cá remetidas como medicamentos oficiais, credenciados pelas autoridades médico-científicas portuguesas.

Vera Marques segue obviamente os passos dos 'atores coadjuvantes', em suas leituras, seus pareceres e nas apropriações que fazem da natureza, fazendo dela uso lícito ou ilícito. Composto por quatro capítulos, Natureza em Boiões apresenta os caminhos e descaminhos dos saberes sobre as plantas medicinais brasílicas: "saíam daqui como saberes incivilizados, 
voltando como o mais genuíno e elaborado conhecimento científico português" (p. 283).

Os dois primeiros capítulos tratam do complexo sistema de leituras e apropriações de saberes por parte dos diversos atores sociais. Os primeiros leitores europeus - cronistas, viajantes e colonizadores não receberam apoio institucional da metrópole. Desbravadores e aventureiros procuraram, nesse primeiro momento, mencionar e descrever a natureza. Aos trancos e barrancos, acajás, ambaigbas, ambaigtingas, andás, caapebas, caapiás,caarabmoçarandigas, camarás e tantas outras plantas vâo sendo reveladas à margem da Coroa portuguesa e à custa dos saberes dos primeiros leitores: os ameríndios (p. 58).

A primeira fase é marcada por iniciativas que Vera Marques chama de "dar a ver". Pouco mais ou pouco menos, as descrições, distantes da taxinomia fundiam as aparências e as utilidades dos produtos da natureza. "Cheiros, gostos e comestibilidade poderiam também servir como referência para organizar conjuntos de plantas, embora o forte fossem mesmo seus usos medicinais" (p. 50).

A autora não deixa de reconhecer a façanha desses primeiros portugueses:

As explorações naturalistas empreendidas durante o governo de Maurício de Nassau têm sido caracterizadas como possuidoras de cunho científico e assinaladas como o marco inaugural dos estudos da natureza no Brasil. Assim, Piso e Marcgrave seriam os pioneiros, fundadores da nosologia e da história natural da América portuguesa. ... Porém, se tais trabalhos realizaram o primeiro intento de buscar uma classificação científica para a natureza no Nordeste do Brasil, os quais foram amplamente publicados e divulgados, faça-se justiça aos primeiros descritores portugueses. Coube a eles a façanha, no caso heróica, de originalmente revelar muitas de nossas plantas (p. 57).

No entanto, os leitores primeiros, os ameríndios, recebem os maiores méritos da autora. Afinal de contas, são eles os responsáveis pelas indicações dadas aos europeus sobre as novas plantas que poderiam servir de alimento ou remédio.

Quando modulada pelo saber científico das luzes, já em meados do século XVIII, aquela leitura ganharia novas características. Esgotados os minérios oriundos das Gerais, a natureza brasílica, a partir de então, deveria ser decifrada, decodificada, para, ao se compreenderem suas leis de funcionamento, torná-la útil ao reino. Novos critérios científicos eram aplicados para a taxinomia das plantas. Os naturalistas passavam a classificá-las pelo sistema proposto, em 1735, pelo botânico Lineu, cujas diferenciações estabeleciam-se pelo sistema de reprodução das plantas (p. 97).

Contrapondo-se à historiografia tradicional, Vera Marques chama atenção para o papel da Academia Médico-Cirúrgica, Botânica e Farmacêutica do Rio de Janeiro, que pouco tinha de literária. Ela tornou-se o espaço de introdução sistemática da filosofia das luzes no além-mar, tentativa de controle da natureza tropical em meio ao espírito de classificação que influenciava o universo iluminista. "Da desconstrução da natureza, constituíam-se discursos para a classificação do mundo natural" (p. 119). 
A segunda fase da interpretação das plantas medicinais continha duas chaves: o cientificismo (característica do ambiente sociocognitivo europeu, contagiado pelas luzes) e o pragmatismo (característica eminentemente ibérica). A leitura da natureza não se resumia naqueles empreendimentos dos primeiros colonizadores e viajantes, fascinados pela sua exuberância. Ela devia ser 'trabalhada': por um lado, para a constituição de 'verdades científicas'; por outro, para tornar-se produto de exploração econômica, fornecendo novos subsídios à metrópole lusa.

Curiosamente, muitas pesquisas, minuciosas, como as de Luís Gomes Ferreira e do frei José Mariano da Conceição Velloso, deixavam de ser publicadas. Eram guardadas a sete chaves nos cofres metropolitanos, evitando-se assim as prováveis usurpações da nova fonte de riquezas. Como afirma Vera Marques, era praxe da política metropolitana muitas das descobertas de naturalistas luso-brasileiros não receberem o reconhecimento em tempo hábil para conferir-lhes os méritos científicos, aparecendo como feitas por terceiros (p. 137).

No terceiro capítulo, 'Boticários setecentistas, a natureza do ofício', Vera Marques aborda o papel dos boticários em meio a esta trama. Agentes oficiais, eram eles no entanto relegados a segundo plano, como detentores de uma arte subalterna, 'cozinheiros dos médicos', na versão coeva de Raphael Bluteau (Vocabulário português e latino, apud Marques, p. 155), e associados, muitas vezes, a pérfidos comerciantes.

Se, no plano do discurso, como a maior parte dos colonizadores, os boticários tenderam a desacreditar os medicamentos da terra (p. 197), na prática eles foram um elo importante na constituição das farmacopéias e nos tratados que se espalharam pelo continente europeu. A autora sustenta o argumento de que, apesar da tendência a rejeitarem tais medicamentos, "os boticários valiam-se de todos os recursos, lançando mão da rica flora existente no país. Para utilizá-la, recorriam aos conhecimentos de todos aqueles que se dedicavam ao ofício de curar" (p. 29).

O último capítulo trata dos remédios com suas fórmulas secretas, que, por um longo tempo, juntaram magia, religião e ciência nos trópicos, acompanhando os referenciais culturais tanto de colonizadores quanto de colonizados, síntese de um contexto sociocognitivo que transitava entre a magia e o cientificismo, em pleno século das luzes. Um médico como Curvo Semedo, considerado inovador e de grande reputação internacional, ao mesmo tempo que fazia uso da química em suas fórmulas, não abandonava os ensinamentos galênicos, além de manter em segredo os componentes de seus medicamentos. Para além disso, algumas de suas receitas poderiam incluir morcegos, sapos, burricos e excrementos (p. 267).

A história social da medicina na colônia é uma área profícua, oferecendo aos pesquisadores inúmeras perspectivas para futuras investigações. O século XVIII é sem dúvida um foco privilegiado de análise. Por essa época, ocorreram importantes transformações, embora persistissem reminiscências de saberes e práticas mágicas e religiosas, tanto originárias do universo simbólico europeu quanto dos povos colonizados.

De fato, como enuncia Vera Marques na introdução de Natureza em Boiões (p. 28), a falta de médicos não justificava por si só as persistências das medicinas praticadas nos trópicos, e que, em pleno século das luzes, 
permanecia repleta de magia e religiosidade. Costuma-se argumentar que tal ausência teria fundamental importância para a proliferação das medidas terapêuticas as mais diversas, tais como as utilizadas por curandeiros, pajés e feiticeiros. Esse ponto de vista acarreta a continuidade de um 'olhar por dentro', como faziam alguns dos 'médicos-historiadores', credenciando os saberes oficiais como se de fato eles fossem capazes de melhor servir a colonos e colonizados do que aqueles praticados pelos curandeiros (p. 282).

Concordo com Vera Marques: mais do que a falta de médicos credenciados, tratava-se da persistência de saberes originários de diversas raízes culturais, referenciais que faziam parte das mentalidades da maior parte da população local, na contínua tentativa de solucionar seus problemas físicos e espirituais.

Para além disso, a falta de médicos não foi característica única e exclusiva da colônia. O curso de medicina, até a reforma pombalina, era considerado o 'menos nobre' entre as faculdades maiores. Houve tentativas de angariar recursos para os alunos dispostos a enveredar por este caminho. Geraramse financiamentos para os estudos, a chamada "arca dos médicos e boticários" - trata-se de uma fonte de financiamento para o pagamento dos partidistas (bolsistas, nos termos atuais), que a universidade arrecadava por meio de contribuições anuais de 15 comarcas do reino - fornecendo 'partidos' para aqueles que se dedicassem ao estudo dos 'humores'. Essa era uma estratégia de fortalecimento da disciplina e de redução das possibilidades para os cristãos-novos, que tendiam a monopolizar a área (Fonseca, 1997, pp. 481-5, 512). Houve também uma proposta de se criar um colégio para médicos, antes e durante o período de permanência dos estudantes na universidade, mas que acabou por fracassar.

De fato, a pouca atração pela faculdade, ao que parece, esteve ligada às oportunidades futuras oferecidas aos formados, no plano socioprofissional, quando comparadas às que eram oferecidas aos que freqüentavam a Faculdade dos Sagrados Cânones. Os físicos tinham poucas alternativas para recrutamento nos setores administrativos, civis ou eclesiásticos. Havia, além da carreira docente, alguns cargos de maior prestígio, como os de físico-mor e cirurgião-mor, de representação régia. Porém, eles eram restritos (pp. 511-8). No que tange à administração local, havia as santas casas, os presídios e as câmaras, nos quais o ingresso também não representava grandes vantagens em comparação às instituições que abrigavam bacharéis em direito canônico (Santos Filho, 1977, vol. I, pp. 234-58). As alternativas para os que se formavam em Portugal eram as de se tornar médicos particulares da família real ou mesmo das camadas da nobreza de maior projeção na Corte. O mais freqüente, porém, foi o exercício da clínica particular.

Os dois primeiros séculos de colonização mereceriam maiores investigações, no que tange aos representantes da medicina oficial que por aqui estiveram. Sabe-se que desde meados do século XVII ocorreu um aumento gradativo da freqüência de colonos na Universidade de Coimbra (Morais, 1949). Talvez essa instituição tenha servido como centro de formação e de socialização, que pode ter sido fundamental para homogeneizar e diferenciar o status daqueles que praticavam a arte oficial nos trópicos. 
Cabem ainda avaliações dos centros de treinamento e sociabilidade no Novo Mundo, principalmente no período anterior ao surgimento das primeiras academias literárias ou científicas do século XVIII. As confrarias religiosas e laicas podem ter representado loci de sociabilidade de agentes de determinados ofícios, como a de São Cosme e São Damião, que reunia médicos, tanto em Portugal quanto no Brasil (Carvalho, 1928). Sabe-se também do papel das santas casas da Misericórdia, presentes em quase todas as cidades e vilas do império português, onde médicos e cirurgiões completavam sua formação por meio da realização de atividades práticas (Santos Filho, 1977, p. 242).

Vera Marques (pp. 215-8) chama atenção para o papel exercido pelas boticas como centros aglutinadores de boêmios e letrados, de onde muitas vezes emergiam discussões políticas. Ressalta também a falta de estudos sobre esses pólos privilegiados de sociabilidade nas grandes cidades coloniais.

Fica a impressão da necessidade de utilização de documentos de origem eclesiástica e notarial para a compreensão do cotidiano e da prática da cura dos agentes da medicina tradicional ibérica, daqueles que não produziram grandes obras, que não foram acusados de feitiçaria, de magia etc., mas que transitaram pela Europa, onde freqüentaram universidades, e que por aqui estiveram praticando seus ofícios. Infelizmente, estudos dessa natureza ainda permanecem enuviados, seja pela ênfase da historiografia na produção intelectual dos mais conceituados médicos e naturalistas do Império, seja pelos aspectos relacionados à excentricidade dos saberes e das práticas medicinais na colônia.

Nesse sentido, ainda seguindo os passos de Vera Marques, valeria a pena realizar estudos pormenorizados desses agentes oficiais, verificando sua bagagem cultural e teórica e o status que lhes conferia as configurações sociais nas quais se inseriam, mais do que recair na tradicional e oficial avaliação (que por si só já parte de uma visão anacrônica que ‘olha por dentro' a prática desses agentes) das mazelas dos trópicos, pela sua ausência.

Considero os melhores trabalhos acadêmicos aqueles que abrem perspectivas para novas investigações. E este é um mérito de Natureza em Boiões. Embora seu foco de análise esteja na importância da flora brasileira na constituição da ciência farmacêutica moderna, nas entrelinhas podem-se ler algumas diretrizes para a continuidade de pesquisas na área das medicinas coloniais, até pouco tempo relegadas pela historiografia mais afeita aos estudos relacionados à segunda metade do século XIX e aos períodos subseqüentes. 


\section{REFERÊNCIAS BIBLIOGRÁFICAS}

Carvalho, Augusto da Silva

1928

Fonseca, Fernando

Taveira da

1997

Morais, Francisco de 1949

Ribeiro, Márcia Moisés 1997

Santos Filho,

Lycurgo de Castro 1977
O culto de S. Cosme e S. Damião - em Portugal e no Brasil - História das sociedades médicas portuguesas.

Coimbra, Imprensa da Universidade.

História da universidade em Portugal.

Coimbra/Lisboa, Universidade de Coimbra/Fundação Calouste Gulbenkian, vol. I, tomo II.

'Estudantes da Universidade de Coimbra nascidos no Brasil'. Em Brasilia - Suplemento ao volume IV. Coimbra, FLUC-IEB.

A ciência nos trópicos: a arte médica no Brasil do século XVIII. São Paulo, Hucitec.

História geral da medicina brasileira.

São Paulo, Hucitec/Edusp, vol. 1. 